\title{
Aerobic Exercise Training as a Potential Cardioprotective Strategy to Attenuate Doxorubicin-Induced Cardiotoxicity
}

\author{
Samir A. Kouzi ${ }^{1}$ and Mohammad Nasir Uddin ${ }^{2}$ \\ ${ }^{1}$ School of Pharmacy, Levine College of Health Sciences, Wingate University, Wingate, North Carolina 28174, USA. \\ ${ }^{2}$ Department of Pharmaceutical Sciences, College of Pharmacy, Larkin Health Sciences Institute, Miami, Florida, USA.
}

Received, October 17, 2016; Revised, October 24; Accepted, October 25, 2016, Published October 25, 2016.

\begin{abstract}
Doxorubicin is one of the most commonly used cytotoxic anticancer drugs against several cancers. Although a highly effective anticancer drug, the clinical use of doxorubicin is severely limited by its cardiotoxicity which results in morbidity, poor quality of life, and premature mortality. Only very few clinically accepted methods to minimize doxorubicin-induced cardiac injury are available today, but none of them have proven to be completely successful. Due to limited alternative strategies, a number of potential cardioprotective therapies are currently being investigated for treating and/or preventing doxorubicin-induced cardiotoxicity. Of these potential strategies, aerobic exercise training is the only nonpharmacologic strategy that shows a great deal of promise. Although there are no published human clinical trials, evidence from numerous animal studies suggests that aerobic exercise training, administered prior to, during and/or following doxorubicin therapy, is protective against doxorubicin-induced cardiac injury. Protective properties of exercise training against the cardiotoxicity of doxorubicin have been attributed to a number of potential molecular mechanisms including: enhancing the production of endogenous antioxidant machineries; regulating proapoptotic signaling; stimulating the release, mobilization and homing of cardiac progenitor cells; limiting myocyte turnover; eliciting favorable adaptations in myocardial calcium handling and preventing calcium overload; modulating cardiac AMPK activity; downregulating cardiac autophagy/lysosomal signaling; and reducing myocardial doxorubicin accumulation. Further preclinical and clinical research is needed to decipher and refine the molecular mechanisms underlying the cardioprotective effects of exercise training, as well as to define the nature and magnitude of the effect of exercise on doxorubicin-induced cardiotoxicity in cancer patients.
\end{abstract}

This article is open to POST-PUBLICATION REVIEW. Registered readers (see "For Readers") may comment by clicking on ABSTRACT on the issue's contents page.

\section{INTRODUCTION}

Doxorubicin (DOX) is an anticancer chemotherapy drug which is classified as an "anthracycline antibiotic." It is one of the most commonly used cytotoxic anticancer drugs in clinical practice $[1,2]$. It is a broad-spectrum antitumor agent which has major clinical activity against several cancers such as breast, endometrium, ovary, testicle, thyroid, stomach, bladder, liver, and lung. It also has clinical activity on soft tissue sarcomas and several childhood cancers including neuroblastoma, Ewing's sarcoma, osteosarcoma, and rhabdomyosarcoma. Its clinical activity also has impact on hematologic malignancies, including acute lymphoblastic leukemia, multiple myeloma, and Hodgkin's and non-Hodgkin's lymphomas. It is generally used in combination with other anticancer drugs such as cyclophosphamide, cisplatin, and 5-
FU. The cytotoxic anticancer action of DOX has been attributed to four major mechanisms [3-7]. These are: 1) inhibition of topoisomerase II, which cuts both strands of the DNA helix simultaneously in order to manage DNA tangles and supercoils, affects DNA replication and repair and leads to apoptosis; 2) high-affinity binding to DNA through intercalation, with consequent blockade of the synthesis of DNA and RNA, and DNA strand scission; 3) generation of semi-quinone free radicals and oxygen free radicals which attack DNA and oxidize DNA bases; and 4) binding to cellular membranes to alter fluidity and ion transport. Although effective and commonly used as

\footnotetext{
Corresponding Author: Mohammad Nasir Uddin, Ph.D. Department of Pharmaceutical Sciences; College of Pharmacy; Larkin Health Sciences Institute; Miami, Florida, USA; Email: muddin@ularkin.org
} 
chemotherapeutic agent for several cancers, doxorubicin has a severe adverse effect which limits its use. This major adverse effect is cardiotoxicity which is acute and occurs within 2-3 days of doxorubicin administration [8]. Doxorubicin can also cause cardiomyopathy which is a chronic heart disease, causing the heart muscle to become enlarged, thick or rigid, less functional and weak which can lead to heart failure or arrhythmia. Once developed, the cardiomyopathy carries a poor prognosis and is frequently fatal $[9,10]$. The presently available treatment of established cardiomyopathy does not appear to improve prognosis. Therefore, an effective way to reduce the toxicity is required. Aerobic exercises, including walking, rope jumping, running, swimming, cycling etc., refer to any exercise activity that reinforces the heart and have been shown to attenuate DOXinduced cardiomyopathy. In this review, we provide a brief overview of the nature and mechanisms of DOX-induced cardiotoxicity, evidence from animal studies supporting aerobic exercise training as a potential cardioprotective strategy to attenuate DOX-induced cardiac injury, and the proposed mechanisms for the protective properties of exercise training against DOX-induced cardiac dysfunction.

\section{Doxorubicin-induced cardiotoxicity}

Although a highly effective anticancer drug, the clinical use of DOX is limited by its acute cardiotoxicity. The dose-dependent cardiotoxicity is characterized by acute cardiac injury that may progress to chronic cardiomyopathy and congestive heart failure in months to years following doxorubicin treatment [11]. Doxorubicin is known to trigger dose-dependent, cumulative and progressive cardiac damage that results in left ventricular remodeling (e.g., cavity dilation and decreased global systolic function), decreased left ventricular ejection fraction, and, ultimately, heart failure [12]. The cardiomyopathy and congestive heart failure generally develop after multiple intravenous administrations of doxorubicin over a period of several months in humans. Incidence of chronic cardiomyopathy appears to be highly dependent on the cumulative DOX dose administered [13-15]. Retrospective analyses from clinical trials in adults suggest that the incidence of congestive heart failure due to DOX is $1.7 \%$ at a cumulative dose of 300 $\mathrm{mg} / \mathrm{m}^{2}, 4.7 \%$ at $400 \mathrm{mg} / \mathrm{m}^{2}, 15.7 \%$ at $500 \mathrm{mg} / \mathrm{m}^{2}$, and $48 \%$ at $650 \mathrm{mg} / \mathrm{m}^{2}$ [14]. Clinical trials and animal studies showed that acute myocardial dysfunction occurring at the early phase of DOX treatment is highly predictive of later cardiomyopathy $[16,17]$. These studies further suggest that the chronic manifestations of DOXinduced cardiotoxicity may result from myocardial injuries associated with acute DOX exposure [18]. Thus far multiple mechanisms of DOX-induced cardiotoxicity have been proposed in the literature [19-26]. Among the proposed mechanisms, DOXinduced generation of reactive oxygen species (ROS) is the central mediator of numerous direct and indirect cardiac adverse consequences. The followings are the most widely cited and accepted key mechanisms in DOX-induced cardiotoxicity:

1) Formation of ROS and increased oxidative stress in cardiomyocytes: DOX-induced generation of ROS occurs via multiple pathways including redox cycling of the quinone moiety of DOX, the formation of DOX-iron complexes, downstream effects of topoisomerase II $\beta$ inhibition, and Rac1 signaling [19-22, 26].

2) Accelerated myofilament apoptosis: Myocyte cell death results from DOX-induced generation of ROS, which, in turn, activate numerous signaling pathways that determine cell fate. A key pathway involves activation of the tumor suppressor protein, p53. p53-dependent apoptosis involves transcriptional activation or inhibition of certain target gene pathways such as mitogen activated protein kinases (MAPKs). Studies have shown that $24 \mathrm{~h}$ of DOX exposure induced apoptosis in cardiac myocytes through activation of p38 MAPK and c-Jun N-terminal kinases (JNKs) [27-30]. Inhibitors of p53, p38 MAPK and JNK have all been shown to prevent DOX-induced apoptosis.

3) Suppression of myofilament protein synthesis: This occurs through depletion of cardiac progenitor cells (CPCs) or GATA-4 dependent gene expression. DOX exposure significantly reduces the population of CPCs, leading to impaired myocyte turnover, accumulation of senescent cells, and the onset of ventricular dysfunction. DOX also downregulates GATA-4, a CPC regulatory transcription factor and an essential survival factor for postnatal cardiomyocytes. Decreased GATA-4 levels following DOX exposure may, in turn, inhibit sarcomere protein synthesis, thus contributing to left ventricular dysfunction [3133]. 
4) Ultrastructural changes to myocytes: ROS cause alterations in calcium homeostasis leading to systolic/diastolic dysfunction. DOX stimulates calcium release and inhibits sarcoplasmic reticulum calcium uptake, resulting in cytosolic calcium overload. This calcium overload may contribute to impaired contractile function by promoting release of the proapoptotic factor cytochrome c and/or activating the cysteine protease calpain. Calpains initiate turnover of both regulatory and structural myofibrillar proteins through cleavage and release of large polypeptide fragments [3436]. DOX is also known to significantly degrade the structural protein titin in cardiomyocytes in concert with impaired relaxation [37]. Pretreatment of myocytes with calpain inhibitors $1 \mathrm{~h}$ prior to DOX preserved the ratio of titin to myosin heavy chain similar to control levels, and reduced the DOX-induced myofibrillar disarray [38].

5) Alterations in cardiac energy metabolism: DOX reduces cardiac energy reserves by lowering ATP and phosphocreatine (PCr) levels as well as the PCr/ATP ratio. In the normal heart, AMP-activated protein kinase (AMPK) protects cardiac cells from perturbations in energy homeostasis via activation of catabolic pathways to generate ATP. DOX reduces the levels of AMPK and its basic activation state, leading to decreased phosphorylation of antiacetyl-CoA carboxylase (ACC), an AMPK downstream target [39-43]. Lack of ACC inhibition results in impairment of fatty acid oxidation. The mechanisms underlying inhibition of AMPK are not clear. Prolonged DOX exposure has also been shown to cause alterations in the expression of genes that regulate mitochondrial function, biogenesis, and oxidative phosphorylation, including downregulation of peroxisome proliferatoractivated receptor gamma coactivator (PGC)- $1 \alpha$ and $-1 \beta$. PGC- $1 \alpha$ is an established and critical regulator of oxidative metabolism and may play a role in the pathogenesis of heart failure.

6) Impairment of prosurvival signaling pathways via NRG-1 and ErbB inhibition: DOX therapy renders cardiomyocytes more susceptible to alterations in neuregulin-1 (NRG1) and ErbB signaling and subsequent prosurvival pathways, mediated by phosphoinositide 3-kinase, serine/threonine- specific protein kinase Akt, mitogen-activated protein kinase, and extracellular signal-regulated kinase (ERK) $1 / 2$ signaling cascades. Administration of NRG-1 has been shown to be cardioprotective in DOX-induced cardiotoxicity and, conversely, NRG-1 heterozygotes have decreased survival and cardiac function with DOX exposure compared with wild types. In animal models, acute DOX treatment has been shown to decrease ErbB4, partially mediated by microRNA-146a-induced degradation, but no change in ErbB2 expression was detected [4448].

Cardiotoxicity is a serious adverse complication of DOX therapy leading to morbidity, poor quality of life, and premature mortality. Therefore the most challenging part of DOX therapy is to maximize the anticancer benefits, while keeping the cardiac damage at minimum level. Unfortunately, only very few clinically accepted methods to minimize DOXinduced cardiotoxicity (e.g., dose modification; use of dexrazoxane; therapy discontinuation) are available today and none of them have proven to be completely successful in ameliorating the damaging effects of DOX on the heart, while maintaining its antineoplastic efficacy [24]. Due to limited alternative strategies to reduce cardiac injury, identification and testing of new interventions for preventing and/or treating DOX-induced cardiotoxicity is urgently needed. Effective new interventions for alleviating the cardiotoxic effects of DOX are expected to occur in two different ways; either exploiting the tissue-specific differences between cancerous tissues and the cardiomyocyte/cardiac endothelium or affecting the cardiotoxic mechanisms without disrupting antitumor pathways [25]. Currently, a number of potential cardioprotective therapies are under active investigation for treating and/or preventing DOXinduced cardiotoxicity. These include exercise training, HMG-CoA reductase inhibitors, betablockers, angiotensin receptor blockers, ACE inhibitors, and bivalent neuregulin. Of the potential cardioprotective strategies that are being investigated, aerobic exercise training is the only nonpharmacologic strategy that promises to attenuate DOX-induced cardiac dysfunction significantly [24, 25, 49]. 


\section{Modulation of doxorubicin-induced cardiotoxicity by aerobic exercise training}

Cardioprotective properties of aerobic exercise training are well documented. Aerobic exercise has been shown to improve systolic and diastolic function and attenuate pathologic cardiac remodeling, resulting in improved exercise tolerance and resistance to fatigue during exertion in patients with heart failure [24, 49]. These improvements have been shown to directly promote increases in maximal oxygen uptake, overall quality of life, and prognosis in these patients. The beneficial properties of aerobic exercise in cardiac disease states have triggered a rationale for investigating the efficacy of this type of exercise in preventing (exercising prior to and during DOX therapy) and/or treating (exercising following DOX therapy) DOX-induced cardiotoxicity. As a result, numerous studies examining the protective effects of aerobic exercise training against DOX-induced cardiac injury in animal models have been reported. Of these reports, sixteen animal studies (twelve in rats and four in mice) have already been reviewed in the literature by Scott et al. [24]. Among the sixteen studies, ten of them investigated the effects of exercise prior to DOX therapy, four studies looked at the effects of exercise during concurrent therapy, and two studies examined the efficacy of exercise in treating cardiac injury following DOX therapy. Major findings from these studies indicated that exercise training: 1) prevents DOX-induced impairments in left ventricular systolic and diastolic function, 2) decreases DOX-induced histopathologic myocyte damage, 3 ) protects against changes in maximal and minimal developed pressure velocities, 4) attenuates left ventricular dysfunction following DOX exposure, 5) ablates a DOX-induced increase in atrial naturietic peptide (ANP) and cardiac sarcoplasmic reticulum calcium transporter (SERCA2a), 6) increases survival rate following DOX treatment, and 7) decreases cardiac proapoptotic markers following DOX exposure [24].

In addition to the studies reviewed by Scott et al., ten other animal studies examining the role of aerobic exercise in attenuating DOX-induced cardiotoxicity were disclosed. The design, scope, and major findings of these ten studies are summarized in Table 1 and will be discussed here. Hydock et al. investigated the effects of exercise preconditioning on early chronic DOX-induced cardiotoxicity in rats [50]. In this study, animals were randomly assigned to sedentary, treadmill, or wheel running groups. Treadmill group animals participated in a progressive training protocol for 10 weeks. Similarly, wheel running group participated in voluntary wheel running for 10 weeks. Following the intervention, animals were further randomized to receive either DOX or saline. All animals then remained sedentary for 4 weeks. Results showed that there was much less decline in left ventricular function and mitral and aortic valve blood flow velocities in the treadmill with DOX group and wheel running with DOX group when compared with sedentary animals receiving DOX. In addition, results revealed that treadmill and wheel running prior to DOX treatment protected against a significant decrease in left ventricular developed pressure and maximal rate of pressure development that occurred in the sedentary with DOX group. Exercise cardioprotection was also associated with preserved myosin heavy chain (MHC) but not sarcoendoplasmic reticulum calcium ATPase 2a expression. The study concluded that 10 weeks of prior exercise can protect against early chronic DOX cardiotoxicity, suggesting that training status may be a determining factor in the degree of late-onset cardiotoxicity experienced by cancer patients undergoing treatment with DOX. In another similarly designed study, Hydock et al. examined the effects of exercise preconditioning on acute DOXinduced cardiotoxicity in rats and whether any observed cardioprotection was associated with MHC isoform alterations [51]. Both in vivo and ex vivo results showed that DOX promoted significant cardiac dysfunction at 5 and 10 days after the injection in sedentary animals. This dysfunction was associated with an upregulation of the beta-MHC isoform. Exercise preconditioning was found to be protective against DOX-induced cardiac dysfunction at 5 and 10 days after injection by attenuating betaMHC upregulation. The authors concluded that endurance training prior to DOX treatment is an effective protection against acute DOX cardiotoxicity for up to 10 days, and this protection can potentially be explained by a preservation of MHC isoform distribution. A third study by Hydock et al. investigated the effects of voluntary wheel running during and following DOX treatment using two models of late-onset DOX cardiotoxicity in the rat [52]. Animals received either DOX or saline using one of two separate treatment regimens. These regimens involved either daily or weekly DOX injections with cumulative doses for both protocols totaling $15 \mathrm{mg} / \mathrm{kg}$. Daily DOX doses were $1 \mathrm{mg} / \mathrm{kg}$ 
and lasted for 15 consecutive days while weekly DOX doses were $2.5 \mathrm{mg} / \mathrm{kg}$ and lasted for 6 consecutive weeks. Immediately following the initial DOX/saline dose, animals were randomly housed in cages with voluntary running wheels or standard rat cages throughout DOX/saline treatments and continued until reaching 10 weeks. Results revealed that, when compared with controls, daily DOX reduced running wheel distances at weeks 210 while weekly DOX reduced running wheel distances at weeks 2, 6 and 10. Results also showed that wheel running during and following daily and weekly DOX dosing protected against DOX-induced cardiotoxicity by preserving maximal mitral and aortic blood flow velocities, left ventricular developed pressure, and MHC isoform expression. The authors concluded that reduced volume of activity during and following daily and weekly DOX treatments attenuated DOX-induced cardiac dysfunction, suggesting that low-volume endurance training may be an effective rehabilitative approach in minimizing DOX cardiotoxicity in cancer patients.

Hayward et al. investigated whether exercise training provides cardioprotection in a juvenile rat model of delayed-onset DOX cardiotoxicity [53]. The goal of the study was to shed some light on whether exercise can protect against delayed-onset cardiotoxicity when DOX treatment is initiated in childhood. At 25 days of age, young rats received a doxorubicin dose of $2 \mathrm{mg} / \mathrm{kg}$ for 7 consecutive days (cumulative dose of $14 \mathrm{mg} / \mathrm{kg}$ ). The control group received saline. Animals remained sedentary or were allowed to voluntarily exercise when DOX treatment began. Ten weeks after the initiation of exercise, cardiac function was assessed both in vivo and ex vivo. The study found that DOX treatment stunted normal growth and significantly impaired cardiac function. While voluntary exercise did not offset changes in the growth curve, it did provide significant cardioprotection against DOX-induced cardiotoxicity. It was concluded that exercise training, initiated at the time treatment begins, can protect against delayed-onset DOX-induced cardiotoxicity in adult rats that were treated with DOX as juveniles. In another study, Parry et al. examined the effects of exercise on cardiac function during combined DOX and androgen deprivation therapy (ADT) [54]. ADT, which is administered prior to DOX to preserve testicular function in cancer patients, may exacerbate DOX-induced cardiac injury. Rats received ADT or control implants on days 1 and 29 of the 56-day protocol. Animals remained sedentary or engaged in treadmill endurance exercise beginning on day 1 . On day 15 , the animals received DOX at $1 \mathrm{mg} / \mathrm{kg} / \mathrm{day}$ for 10 consecutive days, or saline. On day 57, cardiac function was assessed in vivo and ex vivo. Animals treated with DOX alone, or with ADT and DOX, showed significant reductions in left ventricular developed pressure $(-21 \%$ and $-27 \%)$, maximal rate of pressure development $(-29 \%$ and $-32 \%)$, and maximal rate of pressure decline $(25 \%$ and $31 \%)$, respectively, when compared with the sedentary control animals. The authors concluded that endurance exercise training attenuated cardiac dysfunction associated with combined ADT and DOX treatment, indicating that exercise during simultaneous ADT and DOX treatment is cardioprotective. Another study by Dolinsky et al. used a murine model of chronic DOX exposure to directly compare the effects of modest aerobic exercise training to resveratrol treatment on DOXinduced cardiotoxicity, exercise performance, and markers of mitochondrial function and oxidative stress resistance [55]. Mice were divided into four groups that received saline, DOX $(8 \mathrm{mg} / \mathrm{kg}$ once a week), DOX with resveratrol (4 $\mathrm{g} / \mathrm{kg}$ diet, ad libitum), and DOX with treadmill exercise (45 min, 5 days/week) for 8 weeks. Results revealed that DOX-induced adverse left ventricular remodeling was partially attenuated by modest exercise and completely prevented by resveratrol. These effects were paralleled by improvements in exercise performance. The results of the study further showed that the cardioprotective effects of exercise training and resveratrol were associated with reduced levels of ANP and the lipid peroxidation byproduct, 4-hydroxy-2-nonenal. In addition, exercise training and resveratrol increased the expression of cardiac sarcoplasmic/endoplasmic reticulum calcium ATPase 2a, superoxide dismutase, mitochondrial electron transport chain complexes, and mitofusin- 1 and -2 in mice administered DOX. The authors concluded that, compared with modest exercise, resveratrol more effectively prevented DOX-induced left ventricular remodeling and was associated with the reduction of DOX-induced oxidative stress.

Ashrafi et al. investigated the effects of shortterm exercise training prior to exposure to two different doses of DOX (10 and $20 \mathrm{mg} / \mathrm{kg}$ ) on biomarkers related to DOX-induced cardiac damage in rats [56]. Animals were randomly assigned into 
control and trained groups. Rats in the trained groups experienced treadmill running of 25-39 min/day, 5 days/week for 3 weeks. At the end of the endurance training, animals received either $10 \mathrm{mg} / \mathrm{kg}$ of DOX, $20 \mathrm{mg} / \mathrm{kg}$ of DOX, or saline. Results of the study showed that three weeks of exercise training prior to DOX exposure significantly increase apelin and superoxide dismutase, and decrease malondialdehyde (MDA), when compared with animals receiving only DOX. The study concluded that pretreatment exercise may improve myocardial tolerance to DOX-induced cardiotoxicity by inhibition of oxidative stress and upregulation of antioxidants in heart tissue. In another similar study, Shirinbayan et al. determined pretreatment effects of moderate-term endurance exercise on heat shock protein $\left(\mathrm{HSP}_{70}\right)$ and biomarkers of cellular oxidative damage in rats [57]. In this study, animals were randomly assigned into control and trained groups. The training program included treadmill running of 25-39 $\mathrm{min} /$ day, 5 days/week for 3 weeks. At the end of the training period, animals received either DOX $10 \mathrm{mg} / \mathrm{kg}$, DOX $20 \mathrm{mg} / \mathrm{kg}$, or saline. The study results revealed that exercise training prior to DOX exposure caused a significant increase in the cardioprotection markers $\mathrm{HSP}_{70}$ and superoxide dismutase, and a decrease in the cardiac damage markers MDA, creatine kinase, and creatine phosphokinase, when compared with animals receiving only DOX. There was no significant difference in the levels of these markers between animals receiving exercise with DOX $10 \mathrm{mg} / \mathrm{kg}$ and animals receiving exercise with DOX $20 \mathrm{mg} / \mathrm{kg}$. The authors concluded that their investigation provides new insights into the biochemical mechanisms by which endurance exercise protects cardiac muscle tissue against DOX-induced toxicity, and suggests that pretreatment with exercise training may be considered as a potentially useful strategy to improve myocardial tolerance against DOX-induced oxidative damage. A study by Smuder et al., on the other hand, investigated the effects of DOX on signaling of the autophagy/lysosomal system in the hearts of sedentary and exercise-trained rats [58]. Evidence suggests that DOX-induced cardiotoxicity is associated with an enhanced production of ROS and oxidative damage, leading to the activation of cellular proteolytic systems. The autophagy/lysosomal proteolytic system is a constitutively active catabolic process that is responsible for the degradation of both organelles and cytosolic proteins. Therefore, the goal of this particular study was to determine whether systemic DOX administration results in altered cardiac gene and protein expression of mediators of the autophagy/lysosomal system, as well as to determine whether exercise training before DOX administration alters the expression of these mediators in cardiac muscle. Rats were randomly assigned to control and exercise-trained groups. Exercise-trained animals performed 5 consecutive days of treadmill running for $60 \mathrm{~min} /$ day. After the final exercise bout, the animals were injected with either DOX $(20 \mathrm{mg} / \mathrm{kg})$ or saline and then killed 24 hours later. Results indicated that DOX treatment increases both the mRNA and protein levels of numerous key autophagy genes, and that exercise training performed before DOX administration inhibits DOX-induced cardiac increases in autophagy signaling/gene expression. Specifically, compared with sedentary DOX-treated animals, the levels of cardiac Beclin-1, Atg12, Atg4, Atg7, LC3, cathepsin $\mathrm{B}$, and cathepsin $\mathrm{L}$ were all reduced in animals that were exercise-trained prior to DOX administration. The study concluded that DOX administration promotes activation of the autophagy/lysosomal system pathway in the heart, and that endurance exercise training before DOX administration is sufficient to block DOX-induced increased autophagy. The authors also stated that, based on their results, endurance exercise training can be a cardioprotective intervention against myocardial DOX-induced toxicity. Finally, Jensen et al. examined whether exercise training reduces cardiac DOX accumulation in rats [59]. Animals were randomly assigned to sedentary, wheel running and treadmill running groups. Trained groups completed 10 weeks of exercise before DOX treatment $(10 \mathrm{mg} / \mathrm{kg}, \mathrm{IP}, 24 \mathrm{~h}$ after the last training session). Subgroups of animals from each group were killed at 1, 3, 5, 7, and 9 days after DOX exposure to assess cardiac function and DOX accumulation. The results showed that ten weeks of exercise preconditioning reduced myocardial DOX accumulation, and this reduction was associated with preserved cardiac function. The authors concluded that the cardioprotective effects of exercise against DOX-induced toxicity may be due, in part, to a reduction in myocardial DOX accumulation. 
Table 1. Summary of recent animal studies examining the role of aerobic exercise training in attenuating doxorubicininduced cardiotoxicity

\begin{tabular}{|c|c|c|}
\hline Study & Intervention & Results \\
\hline $\begin{array}{l}\text { Hydock et al. } \\
\text { [50] }\end{array}$ & $\begin{array}{l}\text { Treadmill and wheel running groups of rats } \\
\text { participated in a progressive training protocol or } \\
\text { voluntary wheel running, respectively, for } 10 \\
\text { weeks, followed by receiving either DOX or } \\
\text { saline. All animals remained sedentary for } 4 \\
\text { weeks following DOX exposure. }\end{array}$ & $\begin{array}{l}\text { Less decline in left ventricular function, mitral and } \\
\text { aortic valve blood flow velocities, left ventricular } \\
\text { developed pressure, and maximal rate of pressure } \\
\text { development was observed in the treadmill with } \\
\text { DOX group and wheel running with DOX group } \\
\text { when compared with sedentary animals receiving } \\
\text { DOX. }\end{array}$ \\
\hline $\begin{array}{l}\text { Hydock et al. } \\
{[51]}\end{array}$ & $\begin{array}{l}\text { Rats were used to examine the effects of } \\
\text { exercise preconditioning on acute DOX-induced } \\
\text { cardiotoxicity in general and MHC isoform } \\
\text { distribution in particular. }\end{array}$ & $\begin{array}{l}\text { DOX-induced cardiac dysfunction was associated } \\
\text { with upregulation of beta-MHC isoform in sedentary } \\
\text { animals. Exercise preconditioning was protective at } \\
5 \text { and } 10 \text { days following DOX exposure by } \\
\text { attenuating beta-MHC upregulation. }\end{array}$ \\
\hline $\begin{array}{l}\text { Hydock et al. } \\
\text { [52] }\end{array}$ & $\begin{array}{l}\text { The study investigated the effects of voluntary } \\
\text { wheel running during and following DOX } \\
\text { treatment using two models of late-onset DOX } \\
\text { cardiotoxicity in rats. Animals received daily or } \\
\text { weekly injections of DOX or saline. Daily DOX } \\
\text { doses were } 1 \mathrm{mg} / \mathrm{kg} \text { for } 15 \text { days; weekly DOX } \\
\text { doses were } 2.5 \mathrm{mg} / \mathrm{kg} \text { for } 6 \text { weeks. }\end{array}$ & $\begin{array}{l}\text { Wheel running during and following daily and } \\
\text { weekly DOX dosing attenuated DOX-induced } \\
\text { cardiac dysfunction by preserving maximal mitral } \\
\text { and aortic blood flow velocities, left ventricular } \\
\text { developed pressure, and MHC isoform expression. }\end{array}$ \\
\hline $\begin{array}{l}\text { Hayward et al. } \\
\text { [53] }\end{array}$ & $\begin{array}{l}\text { The study determined the effects of exercise } \\
\text { training in a juvenile rat model of delayed-onset } \\
\text { DOX cardiotoxicity. } 25 \text { day old rats received } 2 \\
\mathrm{mg} / \mathrm{kg} \text { of DOX on } 7 \text { consecutive days or saline. } \\
\text { Animals then remained sedentary or were } \\
\text { allowed to voluntarily exercise for ten weeks. }\end{array}$ & $\begin{array}{l}\text { Voluntary exercise did provide significant } \\
\text { cardioprotection against delayed-onset DOX- } \\
\text { induced cardiac injury, however, it did not offset } \\
\text { changes in the growth curve when compared with } \\
\text { sedentary animals receiving DOX. }\end{array}$ \\
\hline Parry et al. [54] & $\begin{array}{l}\text { The study examined the effects of treadmill } \\
\text { endurance exercise on cardiac function during } \\
\text { combined DOX and androgen deprivation } \\
\text { therapy (ADT) in rats. Animals received ADT } \\
\text { or control implants on days } 1 \text { and } 29 \text { of the } 56- \\
\text { day protocol; they remained sedentary or } \\
\text { exercised beginning on day } 1 \text {. On day } 15 \text {, } \\
\text { animals received DOX ( } 1 \mathrm{mg} / \mathrm{kg} / \text { day) or saline } \\
\text { for } 10 \text { days. Cardiac function was assessed on } \\
\text { day } 57 \text {. }\end{array}$ & $\begin{array}{l}\text { Treadmill endurance exercise attenuated the adverse } \\
\text { effects of DOX alone or DOX and ADT on left } \\
\text { ventricular developed pressure, maximal rate of } \\
\text { pressure development, and maximal rate of pressure } \\
\text { decline when compared with the sedentary control } \\
\text { animals. }\end{array}$ \\
\hline $\begin{array}{l}\text { Dolinsky et al. } \\
\text { [55] }\end{array}$ & $\begin{array}{l}\text { The study used a murine model of chronic DOX } \\
\text { exposure to compare the effects of modest } \\
\text { exercise training to resveratrol treatment on } \\
\text { DOX-induced cardiotoxicity, exercise } \\
\text { performance, and markers of mitochondrial } \\
\text { function and oxidative stress resistance. Mice } \\
\text { received saline, DOX ( } 8 \mathrm{mg} / \mathrm{kg} \text { once a week), } \\
\text { DOX and resveratrol ( } 4 \mathrm{~g} / \mathrm{kg} \text { diet, ad libitum), or } \\
\text { DOX and treadmill exercise ( } 45 \mathrm{~min}, 5 \\
\text { days/week) for } 8 \text { weeks. }\end{array}$ & $\begin{array}{l}\text { Resveratrol was more effective than modest exercise } \\
\text { in preventing DOX-induced left ventricular } \\
\text { remodeling. Both resveratrol and modest exercise } \\
\text { improved exercise performance and mitochondrial } \\
\text { function and reduced DOX-induced oxidative stress. }\end{array}$ \\
\hline $\begin{array}{l}\text { Ashrafi et al. } \\
{[56]}\end{array}$ & $\begin{array}{l}\text { The effects of short-term exercise training prior } \\
\text { to exposure to two different doses of DOX on } \\
\text { DOX-induced cardiac damage were } \\
\text { investigated in rats. Trained rats experienced } \\
\text { treadmill running of } 25-39 \text { min } / \text { day, } 5 \\
\text { days/week for } 3 \text { weeks. At the end of training, } \\
\text { animals received } 10 \mathrm{mg} / \mathrm{kg} \text { of DOX, } 20 \mathrm{mg} / \mathrm{kg} \\
\text { of DOX, or saline. }\end{array}$ & $\begin{array}{l}\text { Exercise training prior to DOX exposure } \\
\text { significantly increased apelin and superoxide } \\
\text { dismutase and decreased malondialdehyde (MDA) } \\
\text { when compared with animals receiving only DOX. }\end{array}$ \\
\hline
\end{tabular}




\begin{tabular}{|c|c|c|}
\hline $\begin{array}{l}\text { Shirinbayan et } \\
\text { al. [57] }\end{array}$ & $\begin{array}{l}\text { The study determined pretreatment effects of } \\
\text { moderate-term endurance exercise on heat } \\
\text { shock protein }\left(\mathrm{HSP}_{70}\right) \text { and biomarkers of } \\
\text { cellular oxidative damage in rats. Trained } \\
\text { animals experienced treadmill running of } 25-39 \\
\text { min/day, } 5 \text { days/week for } 3 \text { weeks. At the end } \\
\text { of training, animals received DOX } 10 \mathrm{mg} / \mathrm{kg} \text {, } \\
\text { DOX } 20 \mathrm{mg} / \mathrm{kg} \text {, or saline. }\end{array}$ & $\begin{array}{l}\text { Exercise training prior to DOX exposure caused a } \\
\text { significant increase in cardioprotection markers } \\
\text { (HSP }_{70} \text { and superoxide dismutase) and a decrease in } \\
\text { cardiac damage markers (MDA, creatine kinase, and } \\
\text { creatine phosphokinase), when compared with } \\
\text { animals receiving only DOX. No significant } \\
\text { difference was observed in the levels of these } \\
\text { markers between the two DOX doses used. }\end{array}$ \\
\hline $\begin{array}{l}\text { Smuder et al. } \\
{[58]}\end{array}$ & $\begin{array}{l}\text { The effects of exercise training prior to DOX } \\
\text { exposure on autophagy/lysosomal signaling } \\
\text { were examined in rats. Trained rats performed } \\
5 \text { consecutive days of treadmill running for } 60 \\
\text { min/day. At the end of training, animals } \\
\text { received DOX ( } 20 \mathrm{mg} / \mathrm{kg}) \text { or saline and then } \\
\text { killed } 24 \text { hours later. }\end{array}$ & $\begin{array}{l}\text { Exercise training prior to DOX exposure inhibits } \\
\text { DOX-induced cardiac increases in autophagy } \\
\text { signaling/gene expression. }\end{array}$ \\
\hline $\begin{array}{l}\text { Jensen et al. } \\
{[59]}\end{array}$ & $\begin{array}{l}\text { The study investigated whether exercise training } \\
\text { reduces cardiac DOX accumulation in rats. } \\
\text { Animals were randomly assigned to sedentary, } \\
\text { wheel running and treadmill running groups. } \\
\text { Trained groups completed } 10 \text { weeks of exercise } \\
\text { before DOX exposure ( } 10 \mathrm{mg} / \mathrm{kg}, 24 \text { hours after } \\
\text { the last training session). }\end{array}$ & $\begin{array}{l}\text { Ten weeks of exercise preconditioning reduced } \\
\text { myocardial DOX accumulation with preserved } \\
\text { cardiac function. }\end{array}$ \\
\hline
\end{tabular}

Proposed mechanisms for the cardioprotective effects of aerobic exercise training against doxorubicin-induced cardiac injury

Although exercise training has been shown to protect against DOX-induced cardiotoxicity in numerous animal studies, a clear and concise mechanism for its cardioprotective effects is lacking. However, based on these studies, a number of potential molecular mechanisms have been proposed to explain the protective properties of exercise training against DOX-induced cardiac damage [24, 25, 49-59]. The following is a brief description of these proposed mechanisms:

1) Exercise training protects the heart against ROS: This occurs by enhancing the endogenous antioxidant protective machinery, such as glutathione peroxidase 1, catalase, and manganese superoxide dismutase, in cardiac tissue and mitigating DOX-induced ROS formation/release. Exercise-induced increase in heat shock proteins (HSP) 60, 70, and 72 may also contribute, at least partially, to myocardial protection against DOX toxicity. These heat shock proteins can protect cardiomyocytes via different possible mechanisms that include controlling of protein folding, prevention of denaturation and aggregation of intracellular proteins, and acceleration of the breakdown of damaged proteins $[24,25,60]$.

2) Exercise training regulates proapoptotic signaling: Exercise training prevents DOXinduced increases in the activities of the proapoptotic mediators Bax and tissue caspase-3 [61]. Exercise has also been shown to reduce cardiac expression of p53 and apoptotic cardiomyocytes in DOX-treated animals [62].

3) Exercise training may stimulate the release, mobilization, and homing of CPCs and limit myocyte turnover following DOX exposure: Exercise attenuates cardiomyocyte apoptosis, increases CPC proliferation, and augments the presence of KIT positive cells in the heart, leading to a higher abundance of cardiomyocytes in exercised relative to sedentary animals. In addition, aerobic exercise increases GATA-4 mRNA (which prevents cardiomyocyte apoptosis), leading to preservation of cardiomyocyte proliferation and further contributing to the protection against druginduced cardiotoxicity [63].

4) Exercise training elicits favorable adaptations in myocardial calcium handling and prevents calcium overload: Exercise reverses systolic 
and diastolic dysfunction by improving SR calcium release, diastolic SR calcium leak, and SR calcium sequestration. Modulation of calpain activation has also been implicated in exercise-induced protection against DOX cardiotoxicity [64].

5) Exercise training is a potent modulator of AMPK activity in cardiac tissue: AMPK is activated in response to changes in cellular energy, primarily a rise in AMP and a decrease in ATP or PCr. Exercise has been shown to increase total AMPK activity as well as both alpha-isoforms of the catalytic subunit of AMPK and all AMPK downstream targets in the myocardium. Therefore, it is plausible that aerobic exercise may protect cardiac cells against DOX-induced toxicity by potently activating cardiac AMPK, resulting in improved myocardial energetics [65].

6) Exercise training protects against DOXinduced increases in autophagy/lysosomal signaling: Exercise training has been shown to protect against DOX-induced increases in cardiac mitochondrial ROS, mitochondrial damage, proteolysis by calpain and caspase-3, and increased apoptosis. In addition, exercise has also been shown to increase the endogenous antioxidants SOD1, SOD2, glutathione peroxidase-1, and catalase in the heart. As a result, exercise is able to significantly decrease markers of the autophagy/lysosomal system in the heart, which are upregulated by DOX exposure [58].

7) Exercise training reduces myocardial DOX accumulation: Exercise preconditioning was shown to reduce DOX accumulation in the myocardium. The reduction in accumulation was associated with preserved cardiac function [59].

\section{CONCLUSION}

Evidence from numerous animal studies indicates that aerobic exercise is a promising strategy to attenuate DOX-induced cardiac injury. Although exercise has been shown to be beneficial, there are no published human clinical trials to evaluate exercise as an intervention for preventing and/or treating DOX-induced cardiotoxicity in cancer patients. Future preclinical and human clinical studies are certainly needed to: 1) further elucidate the molecular mechanisms underlying the cardioprotective properties of exercise training before, during and after DOX exposure, and 2) specifically define the nature and magnitude of the effect of exercise on DOX-induced cardiotoxicity in cancer patients.

\section{REFERENCES}

1. Weiss RB. The anthracyclines: will we ever find a better doxorubicin? Semin Oncol 1992; 19: 670-686.

2. $\mathrm{Lu} \mathrm{P}$. Monitoring cardiac function in patients receiving doxorubicin. Semin Nucl Med 2005; 35: 197-201.

3. Laurent G, Jaffrezou JP. Signaling pathways activated by daunorubicin. Blood 2001; 98: 913-924.

4. Perego P, Corna E, De Cesare M, Gatti L, Polizzi D, Pratesi G, Supino R, Zunino F. Role of apoptosis and apoptosis-related genes in cellular response and antitumor efficacy of anthracyclines. Curr Med Chem 2001; 8: 31-37.

5. Gewirtz DA. A critical evaluation of the mechanisms of action proposed for the antitumor effects of the anthracycline antibiotics Adriamycin and daunorubicin. Biochem Pharmacol 1999; 57: 727741.

6. Doroshow JH. Effect of anthracycline antibiotics on oxygen radical formation in rat heart. Cancer Res 1983; 43: 460-472.

7. Minotti G, Menna P, Salvatorelli E, Cairo G, Gianni L. Anthracyclines: molecular advances and pharmacologic developments in antitumor activity and cardiotoxicity. Pharmacol Rev 2004; 56: 185229.

8. Chatterjee K, Zhang J, Honbo N, Karliner JS. Doxorubicin Cardiomyopathy. Cardiology 2010; 115: 155-162.

9. Jordon MA. Anti-cancer agents. Cur Med Chem 2002; 2:1-17.

10. Takemura G, Fujiwara H: Doxorubicin-induced cardiomyopathy from the cardiotoxic mechanisms to management. Prog Cardiovasc Dis 2007; 49:330-352.

11. Singal PK, Iliskovic N. Doxorubicin-induced cardiomyopathy. $N$ Engl J Med 1998; 339: 900-905.

12. Singal PK, Li T, Kumar D, Danelisen I, Iliskovic N. Adriamycin-induced heart failure: mechanism and modulation. Mol Cell Biochem 2000; 207: 77-86.

13. Von Hoff DD, Layard MW, Basa P, Davis HLJr, Von Hoff AL, Rozencweig M, Muggia FM. Risk factors for doxorubicin-induced congestive heart failure. Ann Intern Med 1979; 91: 710-717.

14. Swain SM, Whaley FS, Ewer MS. Congestive heart failure in patients treated with doxorubicin: a retrospective analysis of three trials. Cancer 2003; 97: 2869-2879. 
15. Jones LW, Haykowsky MJ, Swartz JJ, Douglas PS, Mackey JR. Early breast cancer therapy and cardiovascular injury. J Am Coll Cardiol 2007; 50: 1435-1441.

16. Monti E, Prosperi E, Supino R, Bottiroli G. Free radical-dependent DNA lesions are involved in the delayed cardiotoxicity induced by Adriamycin in the rat. Anticancer Res 1995; 15: 193-197.

17. Nousiainen T, Jantunen E, Vanninen E, Hartikainen J. Early decline in left ventricular ejection fraction predicts doxorubicin cardiotoxicity in lymphoma patients. Br J Cancer 2002; 86: 1697-1700.

18. Pelikan PC, Weisfeldt ML, Jacobus WE, Miceli MV, Bulkley BH, Gerstenblith G. Acute doxorubicin cardiotoxicity: functional, metabolic, and morphologic alterations in the isolated perfused rat heart. J Cardiovasc Pharmacol 1986; 8: 1058-1066.

19. Horenstein MS, Vander Heide RS, L'Ecuyer TJ. Molecular basis of anthracycline-induced cardiotoxicity and its prevention. Mol Genet Metab 2000; 71: 436-444.

20. Octavia Y, Tocchetti CG, Gabrielson KL, Janssens S, Crijns HJ, Moens AL. Doxorubicin-induced cardiomyopathy: from molecular mechanisms to therapeutic strategies. J Mol Cell Cardiol 2012; 52: 1213-1225.

21. Simunek T, Sterba M, Popelova O, Adamcova M, Hrdina R, Gersl V. Anthracycline-induced cardiotoxicity: overview of studies examining the roles of oxidative stress and free cellular iron. Pharmacol Rep 2009; 61: 154-171.

22. Xu MF, Tang PL, Qian ZM, Ashraf M. Effects by doxorubicin on the myocardium are mediated by oxygen free radicals. Life Sci 2001; 68: 889-901.

23. Zhang S, Liu X, Bawa-Khalfe T, Lu LS, Lyu YL, Liu LF, Yeh ET. Identification of the molecular basis of doxorubicin-induced cardiotoxicity. Nat Med 2012; 18: 1639-1642.

24. Scott JM, Khakoo A, Mackey JR, Haykowsky MJ, Douglas PS, Jones LW. Modulation of anthracyclineinduced cardiotoxicity by aerobic exercise in breast cancer: current evidence and underlying mechanisms. Circulation 2011; 124: 642-650.

25. Hahn VS, Lenihan DJ, Ky B. Cancer therapy-induced cardiotoxicity: basic mechanisms and potential cardioprotective therapies. J Am Heart Assoc 2014; 3: $1-14$.

26. Ky B, Vejpongsa P, Yeh ET, Force T, Moslehi JJ. Emerging paradigms in cardiomyopathies associated with cancer therapies. Circ Res 2013; 113: 754-764.

27. Zhu W, Zou Y, Aikawa R, Harada K, Kudoh S, Uozumi H, Hayashi D, Gu Y, Yamazaki T, Nagai R, Yazaki Y, Komuro I. MAPK superfamily plays an important role in daunorubicin-induced apoptosis of cardiac myocytes. Circulation 1999; 100: 2100-2107.

28. Yamamoto Y, Hoshino Y, Ito T, Nariai T, Mohri T, Obana M, Hayata N, Uozumi Y, Maeda M, Fujio Y,
Azuma J. Atrogin-1 ubiquitin ligase is upregulated by doxorubicin via p38-MAP kinase in cardiac myocytes. Cardiovasc Res 2008; 79: 89-96.

29. Shizukuda Y, Matoba S, Mian OY, Nguyen T, Hwang PM. Targeted disruption of p53 attenuates doxorubicin-induced cardiac toxicity in mice. $\mathrm{Mol}$ Cell Biochem 2005; 273: 25-32.

30. Kang YJ, Zhou ZX, Wang GW, Buridi A, Klein JB. Suppression by metallothionein of doxorubicininduced cardiomyocyte apoptosis through inhibition of p38 mitogen-activated protein kinases. $J$ Biol Chem 2000; 275: 13690-13698.

31. Lewinter MM, Vanburen P. Myofilament remodeling during the progression of heart failure. J Card Fail 2002; 8: S271-S275.

32. De Angelis A, Piegari E, Cappetta D, Marino L, Filippelli A, Berrino L, Ferreira-Martins J, Zheng H, Hosoda T, Rota M, Urbanek K, Kajstura J, Leri A, Rossi F, Anversa P. Anthracycline cardiomyopathy is mediated by depletion of the cardiac stem cell pool and is rescued by restoration of progenitor cell function. Circulation 2010; 121: 276-292.

33. Kim Y, Ma AG, Kitta K, Fitch SN, Ikeda T, Ihara Y, Simon AR, Evans T, Suzuki YJ. Anthracyclineinduced suppression of GATA-4 transcription factor: implication in the regulation of cardiac myocyte apoptosis. Mol Pharmacol 2003; 63: 368-377.

34. Lim CC, Zuppinger C, Guo X, Kuster GM, Helmes M, Eppenberger HM, Suter TM, Liao R, Sawyer DB. Anthracyclines induce calpain-dependent titin proteolysis and necrosis in cardiomyocytes. $\mathrm{J}$ Biol Chem 2004; 279: 8290-8299.

35. Keung EC, Toll L, Ellis M, Jensen RA. L-type cardiac calcium channels in doxorubicin cardiomyopathy in rats: morphological, biochemical, and functional correlations. J Clin Invest 1991; 87: 2108-2113.

36. Saeki K, Obi I, Ogiku N, Shigekawa M, Imagawa T, Matsumoto T. Doxorubicin directly binds to the cardiac-type ryanodine receptor. Life Sci 2002; 70: 2377-2389.

37. Logue SE, Gustafsson AB, Samali A, Gottlieb RA. Ischemia/reperfusion injury at the intersection with cell death. J Mol Cell Cardiol 2005; 38: 21-33.

38. Chen M, Won DJ, Krajewski S, Gottlieb RA. Calpain and mitochondria in ischemia/reperfusion injury. $J$ Biol Chem 2002; 277: 29181-29186.

39. Ingwall JS, Weiss RG. Is the failing heart energy starved? On using chemical energy to support cardiac function. Circ Res 2004; 95: 135-145.

40. Seraydarian MW, Artaza L, Goodman MF. Adriamycin: effect on mammalian cardiac cells in culture. I. Cell population and energy metabolism. $J$ Mol Cell Cardiol 1977; 9: 375-382.

41. Hartiala JJ, Mostbeck GH, Foster E, Fujita N, Dulce MC, Chazouilleres AF, Higgins CB. Velocityencoded cine MRI in the evaluation of left ventricular diastolic function: measurement of mitral valve and 
pulmonary vein flow velocities and flow volume across the mitral valve. Am Heart J 1993; 125: 10541066.

42. Tokarska-Schlattner M, Zaugg M, da Silva R, Lucchinetti E, Schaub MC, Wallimann T, Schlattner U. Acute toxicity of doxorubicin on isolated perfused heart: response of kinases regulating energy supply. Am J Physiol Heart Circ Physiol 2005; 289: H37H47.

43. Finck BN, Kelly DP. Peroxisome proliferatoractivated receptor gamma coactivator-1 (PGC-1) regulatory cascade in cardiac physiology and disease. Circulation 2007; 115: 2540-2548.

44. Bian Y, Sun M, Silver M, Ho KK, Marchionni MA, Caggiano AO, Stone JR, Amende I, Hampton TG, Morgan JP, Yan X. Neuregulin-1 attenuated doxorubicin-induced decrease in cardiac troponins. Am J Physiol Heart Circ Physiol 2009; 297: H1974H1983.

45. Fukazawa R, Miller TA, Kuramochi Y, Frantz S, Kim YD, Marchionni MA, Kelly RA, Sawyer DB. Neuregulin-1 protects ventricular myocytes from anthracycline-induced apoptosis via erbB4dependent activation of PI3-kinase/Akt. J Mol Cell Cardiol 2003; 35: 1473-1479.

46. Liu FF, Stone JR, Schuldt AJ, Okoshi K, Okoshi MP, Nakayama M, Ho KK, Manning WJ, Marchionni MA, Lorell BH, Morgan JP, Yan X. Heterozygous knockout of neuregulin-1 gene in mice exacerbates doxorubicin-induced heart failure. Am J Physiol Heart Circ Physiol 2005; 289: H660-H666.

47. Liu X, Gu X, Li Z, Li X, Li H, Chang J, Chen P, Jin J, Xi B, Chen D, Lai D, Graham RM, Zhou M. Neuregulin-1/erbB-activation improves cardiac function and survival in models of ischemic, dilated, and viral cardiomyopathy. J Am Coll Cardiol 2006; 48: 1438-1447.

48. Horie T, Ono K, Nishi H, Nagao K, Kinoshita M, Watanabe S, Kuwabara Y, Nakashima Y, TakanabeMori R, Nishi E, Hasegawa K, Kita T, Kimura T. Acute doxorubicin cardiotoxicity is associated with miR-146a-induced inhibition of the neuregulin-ErbB pathway. Cardiovasc Res 2010; 87: 656-664.

49. Scott JM, Koelwyn GJ, Hornsby WE, Khouri M, Peppercorn J, Douglas PS, Jones LW. Exercise therapy as treatment for cardiovascular and oncologic disease after a diagnosis of early-stage cancer. Semin Oncol 2013; 40: 218-228.

50. Hydock DS, Lien CY, Jensen BT, Schneider CM, Hayward R. Exercise preconditioning provides longterm protection against early chronic doxorubicin cardiotoxicity. Integr Cancer Ther 2011; 10: 47-57.

51. Hydock DS, Lien CY, Schneider CM, Hayward R. Exercise preconditioning protects against doxorubicin-induced cardiac dysfunction. Med Sci Sports Exerc 2008; 40: 808-817.
52. Hydock DS, Lien CY, Jensen BT, Parry TL, Schneider CM, Hayward R. Rehabilitative exercise in a rat model of doxorubicin cardiotoxicity. Exp Biol Med (Maywood) 2012; 237: 1483-1492.

53. Hayward R, Lien CY, Jensen BT, Hydock DS, Schneider CM. Exercise training mitigates anthracycline-induced chronic cardiotoxicity in a juvenile rat model. Pediatr Blood Cancer 2012; 59: 149-154.

54. Parry TL, Hydock DS, Jensen BT, Lien CY, Schneider CM, Hayward R. Endurance exercise attenuates cardiotoxicity induced by androgen deprivation and doxorubicin. Can $J$ Physiol Pharmacol 2014; 92: 356-362.

55. Dolinsky VW, Rogan KJ, Sung MM, Zordoky BN, Haykowsky MJ, Young ME, Jones LW, Dyck JRB. Both aerobic exercise and resveratrol supplementation attenuate doxorubicin-induced cardiac injury in mice. Am $J$ Physiol Endocrinol Metab 2013; 305: E243-E253.

56. Ashrafi J, Roshan VD. Is short-term exercise a therapeutic tool for improvement of cardioprotection against DOX-induced cardiotoxicity? An experimental controlled protocol in rats. Asian Pac J Cancer Prev 2012; 13: 4025-4030.

57. Shirinbayan V, Roshan VD. Pretreatment effect of running exercise on $\mathrm{HSP}_{70}$ and DOX-induced cardiotoxicity. Asian Pac J Cancer Prev 2012; 13: 5849-5855.

58. Smuder AJ, Kavazis AN, Min K, Powers SK. Doxorubicin-induced markers of myocardial autophagic signaling in sedentary and exercise trained animals. J Appl Physiol 2013; 115: 176-185.

59. Jensen BT, Lien CY, Hydock DS, Schneider CM, Hayward R. Exercise mitigates cardiac doxorubicin accumulation and preserves function in the rat. $J$ Cardiovasc Pharmacol 2013; 62: 263-269.

60. Ascensao A, Ferreira R, Magalhaes J. Exerciseinduced cardioprotection - biochemical, morphological and functional evidence in whole tissue and isolated mitochondria. Int J Cardiol 2007; 117: 16-30.

61. Ascensao A, Magalhaes J, Soares JM, Ferreira R, Neuparth MJ, Marques F, Oliveira PJ, Duarte JA. Moderate endurance training prevents doxorubicininduced in vivo mitochondriopathy and reduces the development of cardiac apoptosis. Am J Physiol Heart Circ Physiol 2005; 289: H722-H731.

62. Werner C, Hanhoun M, Widmann T, Kazakov A, Semenov A, Poss J, Bauersachs J, Thum T, Pfreundschuh M, Muller P, Haendeler J, Bohm M, Laufs U. Effects of physical exercise on myocardial telomere-regulating proteins, survival pathways, and apoptosis. J Am Coll Cardiol 2008; 52: 470-482.

63. Force T, Kerkela R. Cardiotoxicity of the new cancer therapeutics - mechanisms of, and approaches to, the problem. Drug Discov Today 2008; 13: 778-784. 
64. Frensh JP, Hamilton KL, Quindry JC, Lee Y, Upchurch PA, Powers SK. Exercise-induced protection against myocardial apoptosis and necrosis: MnSOD, calcium-handling proteins, and calpain. FASEB J 2008; 22: 2862-2871.
65. Coven DL, Hu X, Cong L, Bergeron R, Shulman GI, Hardie DG, Young LH. Physiological role of AMPactivated protein kinase in the heart: graded activation during exercise. Am J Physiol Endocrinol Metab 2003; 285: E629-E636. 